\title{
A PREVALÊNCIA DO PRINCÍPIO DA ISONOMIA SOBRE O PRINCÍPIO DA NÃO CUMULATIVIDADE QUANDO DA IMPORTAÇÃO DE VEÍCULO AUTOMOTOR PARA USO PRÓPRIO
}

\section{THE PREVALENCE OF THE PRINCIPLE OF ISONOMY OVER THE PRINCIPLE OF NONCUMULATIVE IN AUTOMOTIVE VEHICLE IMPORTS FOR OWN USE}

\author{
${ }^{1}$ Antônio Carlos Diniz Murta \\ ${ }^{2}$ Luisa Mendonça Albergaria De Carvalho
}

\section{RESUMO}

O trabalho aborda a incidência do IPI na importação de veículos automotores por pessoa natural para uso próprio. Discutirá características do procedimento de importação, bem como o Imposto de Importação e, assim, analisará o porque da cobrança destes dois tributos na compra de veículos automotores do exterior. Os conceitos bis in idem e bitributação serão debatidos. Hipóteses de incidência do IPI serão estudadas, demonstrando como o importador pode ser enquadrado como sujeito passivo na tributação do IPI na importação, juntamente comparado nos princípios tributários constitucionais. Por fim, será feita reflexão crítica do recente julgado e novo posicionamento do STF.

Palavras-chave: Ipi, Ii, Veículos automotores, Princípios, Bis in idem

\begin{abstract}
This work deals with IPI's incidence on imports of motor vehicles for personal use. Will be discussed characteristics of the import procedure, import duty, and analyzed the reason for the collection of these two taxes on the import of motor vehicles. The concepts bis in idem and double taxation will be discussed. IPI's incidence cases will be studied, demonstrating how the importer can be classified as a taxable person in the taxation of IPI on imports, along compared the constitutional tax principles. Finally, it will be done a critical reflection of the recent decision and new positioning of STF.
\end{abstract}

Keywords: Ipi, Ii, Auto-vehicles, Principles, Bis in idem

\footnotetext{
${ }^{1}$ Professor Titular de Direito da Universidade FUMEC, Fundação Mineira de Educação e Cultura - MG, (Brasil). E-mail: acmurta@ fumec.br

${ }^{2}$ Mestranda em Direito pela Universidade FUMEC, Fundação Mineira de Educação e Cultura - MG, (Brasil).

E-mail:_albergariaadvocacia@gmail.com
} 


\section{INTRODUÇÃO}

Este trabalho almeja discutir, tendo como problema central, a incidência do Imposto sobre Produtos Industrializados nas importações de veículos automotores realizadas por pessoas naturais.

Para isto, esta pesquisa utiliza como hipótese a incidência do Imposto sobre Produtos Industrializados nas importações de veículos automotores por pessoa natural, ainda que esta não desempenhe atividade empresarial e o faça para uso próprio, tendo como fundamento o fato de que a cobrança do IPI não afronta o princípio da não cumulatividade nem implica bitributação. A Suprema Corte entende ainda que a manutenção de sua incidência preserva o princípio da isonomia, uma vez que promove igualdade de condições tributárias entre o fabricante nacional, já sujeito ao imposto em território nacional, e o fornecedor estrangeiro.

Com o advento da Emenda Constitucional 33/01, que alterou a redação do artigo 155 da $\mathrm{CR} / 88$, foi determinada a incidência do ICMS sobre a entrada de bens ou mercadorias importados do exterior, por pessoa física ou jurídica. Como a EC 33/01 trata do ICMS e, por analogia, o IPI, esta modificação legal passou a valer também para a cobrança do Imposto sobre Produtos Industrializados (IPI) na importação de carro por pessoa física.

Este entendimento consolidou-se na decisão proferida no julgamento do Recurso Extraordinário 723651, onde um contribuinte questionou a decisão do Tribunal Regional Federal da $4^{\mathrm{a}}$ Região (TRF-4) que manteve a cobrança do referido tributo.

Inicialmente será feito um estudo à respeito dos impostos IPI e II, demonstrando suas principais características, bem como suas hipóteses de incidência e justificando em seguida o porque hoje, após decisão proferida pelo STF, é mais vantajoso que uma pessoa física compre veículo no Brasil ao invés de importá-lo do exterior.

Logo após, serão abordados os conceitos de bitributação e bis in idem, com suas respectivas particularidades. Pretende-se também fazer uma breve explanação á respeito da modulação dos efeitos da decisão do STF para o cálculo da cobrança do IPI.

Nesse contexto, o artigo tem como objetivo geral analisar a cobrança do Imposto sobre Produtos Industrializados na importação de veículos automotores para uso próprio através da decisão do Supremo Tribunal Federal, especificamente, examinando o RE 723651, que teve seu julgamento iniciado, mas não finalizado pelo Ministro Barroso. Os princípios tributários constitucionais que versam sobre a temática serão analisados e servirão como subsídio para fundamentar a hipótese. 
Desse modo, a fim de que o objetivo geral possa ser atendido, o artigo propõe-se, em seus objetivos específicos: distinguir e caracterizar a bitributação e o bis in idem, ilustrar a recente decisão que levou ao STF julgar como legítima a cobrança do IPI no caso em questão, relacionar e estabelecer a diferença entre se comprar um veículo no Brasil e importar o mesmo do exterior e enfatizar e defender que hoje, não é mais vantajoso comprar veículos fora do nosso país.

Justifica-se o estudo do tema em razão das consequências que a autorização da cobrança do IPI na importação de veículos automotores pode trazer, tanto de cunho positivo como negativo para a sociedade brasileira. Ressalta-se ainda que, o presente artigo, não se propõe a esgotar o tema debatido.

$\mathrm{Na}$ metodologia, utiliza-se de método dedutivo, do qual se extraem noções gerais acerca da Teoria do Direito Tributário a fim de confirmar a particularidade do ponto de vista do pesquisador.

Ao final, serão apresentadas as divergências enfrentadas pelo Poder Judiciário, que levaram ao reconhecimento da repercussão geral pelo Supremo Tribunal Federal da incidência do Imposto sobre Produtos Industrializados na importação de veículos por pessoa natural para uso próprio no Recurso Extraordinário n. 723.651.

Diante ao exposto, mostra-se de suma importância o desenvolvimento deste trabalho, em que se busca demonstrar que, como já adiantado, o Imposto sobre Produtos Industrializados incide na importação de bens automotores realizada por pessoa natural para uso próprio, uma vez que tal cobrança é juridicamente possível, mesmo caracterizando um bis in idem, porque este não é constitucionalmente proibido.

\section{DESENVOLVIMENTO}

\section{DO IMPOSTO SOBRE OPERAÇÕES COM PRODUTOS INDUSTRIALIZADOS}

\subsection{Características}

Previsto na Constituição de 1988, em seu artigo 153, IV e nos artigos 46 a 51 do CTN, podendo também ser encontrado nas Súmulas 360 e 411 do STJ e 591 do STF, o imposto sobre operações com produtos industrializados (IPI) é de competência da União Federal e é responsável pela segunda maior arrecadação deste ente, perdendo apenas para o imposto de 
renda. Sofre repartição de receita tributária com os Estados e Municípios com o objetivo de reduzir o federalismo assimétrico.

Conhecido antigamente como imposto sobre o consumo, o IPI, regulamentado atualmente pelo Decreto 7.212/10, incide sobre as operações com produtos industrializados e não sobre o processo de industrialização.

O CTN entende como produtos industrializados aqueles produtos que tenham sido submetidos a quaisquer operações que lhes modifiquem a natureza ou a finalidade, ou o aperfeiçoe para o consumo.

O IPI possui como características o caráter de extrafiscalidade, ou seja, serve como instrumento de controle da União na economia e possui uma forte função regulatória ou interventiva na economia brasileira. É seletivo, pois sua alíquota varia em função da essencialidade do produto, fazendo com que os bens essenciais tenham menor alíquota em relação aos bens supérfluos, diferenciando com isso do ICMS que poderá ou não ser seletivo. É real por incidir em razão da coisa, do objeto de tributação. Não é vinculado e tampouco cumulativo. É indireto por permitir o repasse do encargo financeiro do tributo. Proporcional, plurifásico ( incide em todas as etapas da cadeia de circulação) e, por precisar de celeridade na sua variação de alíquota, se encaixa como exceção à legalidade tributária bem como ao principio da anterioridade. Ainda, no art. 18 do Decreto 7.212/10, se encontram as hipóteses onde as incidências do IPI são imunes.

Este imposto é lançado por homologação, de acordo com o art. 150 do CTN, podendo também, conforme art.149 do CTN, ser lançado de oficio. Possuí como fato gerador as hipóteses elencadas no artigo 46 do referido código e, no artigo 38 do Decreto 7.212/10 podemos visualizar quais são as hipótese de não existência de fato gerador do mesmo.

\subsection{Do fato gerador e as hipóteses de incidência do IPI}

Inicialmente cabe salientar que a expressão fato gerador não equivale á expressão hipótese de incidência do tributo. Fato gerador quer dizer uma situação concreta, sólida, que faz nascer o dever de pagar o tributo. Já a hipótese de incidência representa a descrição que há de ser feita pela lei daquela situação capaz de fazer nascer o dever de pagar o tributo. A hipótese de incidência do imposto é a descrição, feita pelo legislador ordinário, da situação de fato cuja concretização fará nascer a obrigação tributária correspondente É possível que um imposto tenha 
mais de uma hipótese de incidência. Desde que todas estejam compreendidas no que denominamos âmbito constitucional desse imposto, nada se pode opor.

O professor Hugo de Brito Machado, em seu livro Curso de Direito Tributário, distingue estes termos da seguinte forma:

“A expressão hipótese de incidência designa com maior propriedade a descrição, contida na lei, da situação necessária e suficiente ao nascimento da obrigação tributária, enquanto a expressão fato gerador diz da ocorrência, no mundo dos fatos, daquilo que está descrito na lei. A hipótese é simples descrição, é simples previsão, enquanto o fato é a concretização da hipótese, é o acontecimento do que fora previsto." (MACHADO, Hugo de Brito. Curso de Direito Tributário. 30 ed. São Paulo: Malheiro Editores, 2009. P.128)

O artigo 46 do CTN dispõe como, fato gerador do IPI, o desembaraço aduaneiro do produto industrializado, a arrematação de produto industrializado em leilão e a saída de industrializado do estabelecimento industrial ou equiparado a industrial.

No caso das hipóteses de incidência, o IPI apresenta várias hipóteses a partir da análise de critérios. Humberto Bonavides Borges, em seu livro Manual de procedimentos tributários, os classifica como:

a) Critério Material: promover a industrialização de um produto e, com ele, realizar um ato ou negócio jurídico relativo à transferência de sua posse ou propriedade; efetuar a importação de produto industrializado do exterior, em harmonia com as condições legais pertinentes.

b) Critério Espacial: qualquer lugar do território nacional, ressalvadas as regiões privilegiadas por lei (por ex. Zona Franca de Manaus); repartições alfandegárias do território nacional habilitadas a proceder ao desembaraço aduaneiro;

c) Critério Temporal: instante da saída do produto individualizado em decorrência de negócio jurídico realizado; ocasião do desembaraço aduaneiro.

\subsection{Das hipóteses de incidência do Imposto sobre Produtos industrializados na importação de veículos por pessoa natural para uso próprio}

Após leitura dos artigos 46, I e 51, I ambos do CTN, pode-se concluir que a importação de veículos automotores por pessoa natural para uso próprio se encaixa perfeitamente como hipótese de incidência do IPI. 
Grande parte da doutrina entende que, independentemente da destinação específica da importação do produto, podendo ser ela comercial ou não, é cabível a incidência do tributo em tela. Essa é a posição atual do Supremo Tribunal Federal ${ }^{1}$ que decidiu, no último dia 3 de fevereiro do corrente ano, sobre a incidência do imposto sobre importações de veículos por pessoa natural ainda que esta não desempenhe atividade empresarial e o faça para uso próprio. Fato este, comprovado pelo provimento negado ao Recurso Extraordinário de número 723.651, cuja ementa se encontra a baixo:

IPI - IMPORTAÇÃO - PESSOA NATURAL - AUTOMÓVEL -
AUSÊNCIA DE ATIVIDADE EMPRESARIAL DE VENDA -
AFASTAMENTO PELO JUÍZO - INCIDÊNCIA DO TRIBUTO
RECONHECIDA NA ORIGEM - RECURSO EXTRAORDINÁRIO -
REPERCUSSÃO GERAL CONFIGURADA. Possui repercussão geral a
controvérsia acerca da incidência do Imposto Sobre Produtos Industrializados
- IPI na importação de veículo automotor, quando o importador for pessoa
natural e o fizer para uso próprio, considerados ainda os limites da lei
complementar na definição do sujeito passivo. (RE 723651 RG / RS - RIO
GRANDE DO SUL REPERCUSSÃO GERAL NO RECURSO
EXTRAORDINÁRIO Relator: Min. MARCO AURÉLIO. Julgamento:
11/04/2013).

A Fazenda Pública do Município de Porto Alegre alegou ainda que, se o tributo IPI não fosse cobrado, a indústria nacional ficaria em desvantagem, a livre concorrência estaria ameaçada e as montadoras brasileiras sofreriam grandiosos prejuízos.

Nesse sentido, Marcus de Freitas Gouvêa analisa as medidas tributárias protetivas promovidas pelo Estado, visando a proteger a indústria local, sendo que:

\begin{abstract}
(...) o tratamento tributário conferido a bens importados possui duas etapas que não se excluem: uma delas voltada à proteção do mercado interno, denominada nacionalização do bem (incidência dos tributos internos), e outra relacionada à proteção do mercado interno (incidência do imposto de importação) - registre-se, apenas, que não se preocupa, aqui, em definir o momento das etapas, que podem ser contemporâneas ou ter sua ordem invertida, conforme o procedimento de importação. A outra etapa de tributação de bens importados é a incidência do imposto de importação, com a finalidade óbvia de proteção do mercado interno. Contudo, se se afasta a incidência de uma das etapas de tributação, excluindo-se, por exemplo, a incidência de tributos internos, além da perda de eficácia dos tributos na nacionalização do produto importado, também o imposto de importação perderá sua finalidade protetora, na medida em que exercerá o papel que os tributos internos não conseguiram desempenhar. (GOUVÊA, 2011, p. 89) .
\end{abstract}

1 A íntegra dos dois textos publicados no site do Supremo a respeito do tema discutido é encontrada no informativo de número
813 , disponível no site: $<$ http://www.stf.jus.br/arquivo/informativo/documento/informativo813.htm. $>$ Acesso em: 7 de março de 2016. 
O princípio da não-cumulatividade, previsto no artigo $153, \S 3^{\circ}$, inciso II da Constituição de 1988, é obrigatório para o Imposto sobre Produtos Industrializados. Por não ser cumulativo, o IPI será compensado no que for devido em cada operação juntamente com o montante cobrado nas anteriores. Ricardo Alexandre, define este princípio da seguinte maneira:

\begin{abstract}
A não cumulatividade é técnica que tem por objetivo limitar a incidência tributária nas cadeias de produção e circulação mais extensas, fazendo com que, a cada etapa da cadeia, o imposto somente incida sobre o valor adicionado nessa etapa. Assim, no final da cadeia, o tributo cobrado jamais

será maior que o valor da maior alíquota, multiplicado pelo valor final da mercadoria.( ALEXANDRE, Ricardo. Direito tributário esquematizado. 6 ed. Rio de Janeiro: Forense; São Paulo: Método, 2012, p. 547.)
\end{abstract}

Dando continuidade ao seu raciocínio, o autor supracitado ainda reforça que, na prática, o imposto exigido na operação anterior é abatido, de modo que, o tributo não se acumule ao longo das operações subsequentes e se evite a incidência em cascata. O princípio da nãocumulatividade com isso impede a oneração excessiva da atividade produtiva, de forma que somente onera a parcela da produção à medida que a mesma ocorre.

\begin{abstract}
A técnica da não cumulatividade visa a evitar, portanto, uma tributação em cascata na cadeia produtiva. Isso está claro na Constituição. Entretanto, não há que se falar em cumulatividade quando é desonerada a etapa anterior ou posterior da cadeia e o efeito cascata não poderia ocorrer em momento futuro algum. Não há qualquer indicativo legal de que a exigibilidade do imposto fique suspensa toda vez que a operação não permitir um crédito, tanto que a jurisprudência oscila quanto a validação do direito ao crédito em operações isentas, e o STF já decidiu que não há compensação de crédito de IPI em operações de aquisição de matériaprima não tributada ou com alíquota zero.
\end{abstract}

\title{
2 IMPOSTO DE IMPORTAÇÃO
}

O Imposto de Importação, também conhecido como Tarifa Aduaneira, é de competência da União Federal, está disposto no art. 153, I, e paragrafo primeiro da Constituição federal, na lei 8.032/90, no Decreto número 6.759/09, e nos artigos 19 a 22 do CTN.

Este imposto, lançado por homologação, é essencial e imprescindível para a proteção da indústria nacional, uma vez que ele visa proteger a economia interna, através da realização do 
princípio da seletividade, que torna mais caros produtos importados taxados como supérfluos, estimulando com isso o a indústria nacional e garantindo o desenvolvimento econômico e financeiro de nossa nação.

O Imposto de Importação exerce função nitidamente extrafiscal uma vez que visa proteger a indústria nacional dos produtos importados que, sem a incidência de tal tributo, chegariam em território nacional com preços bem reduzidos, resultantes de uma produção em tecnologia avançada e racionalizada dos países desenvolvidos, além de uma subsidiariedade de outros países envolvidos na exportação.

Como sujeito ativo deste imposto, temos a União Federal, que instituí e cobra do importador, sendo este definido por Hugo de Brito Machado, como sendo: qualquer pessoa, natural ou jurídica, regularmente estabelecida ou não, que realize a introdução da mercadoria no território nacional, ou a quem a ele a lei equiparar, conforme disposto no art. 22, I do CTN, o imposto em tela. (MACHADO, Hugo de Brito. Curso de Direito Tributário. 27 ed. São Paulo: Malheiros, 2006.)

O fato gerador do Imposto de Importação, descrito no art. 19 do CTN, é caracterizado pela importação e entrada de produto estrangeiro em território nacional. Há porém, parte da doutrina que defende que o fato gerador do tributo em questão somente se configura com o registro de importação emitido pelo SISCOMEX. Ressalta-se que, este documento não será o fato gerador propriamente dito, configurando apenas e tão somente a exteriorização dele.

\section{COBRANÇA DE IPI NA IMPORTAÇÃO DE PRODUTO INDUSTRIALIZADO É CAUSA DE BITRIBUTAÇÃO OU BIS IN IDEM?}

Inicialmente, faz-se necessária a distinção entre os institutos da bitributação e bis in idem. A bitributação é considerada como sendo tributação inconstitucional e significa, segundo Maristela Sabbag, a cobrança de tributos por pessoas políticas distintas, uma delas exorbitando nas atribuições que lhes são conferidas, em decorrência de um único fato gerador. "São duas normas, cada qual emanada de um legislativo, incidindo sobre o mesmo fato jurídico e onerando o mesmo contribuinte" (SABBAG, Maristela Miglioli. In RT. Competência tributária. São Paulo, jun. 1996, v. 728, p. 695).

Por sua vez, a autora supracitada classifica o bis in idem como sendo a cobrança de um mesmo ente político de tributos diversos de um contribuinte, em decorrência de um 
mesmo fato gerador e em razão da incidência de duas normas legais distintas. (SABBAG, Maristela Miglioli. In RT. Competência tributária. São Paulo, jun. 1996, v. 728, p. 695).

Neste sentido, Igor Tenório e José Motta Maia conceituam os institutos como:

“ A distinção de multiplicidade de tributação, no Direito Tributário Nacional, entre bitributação e bis in idem, já não oferece dúvidas ou problemas de qualquer natureza, tão definidos estão os conceitos: a dupla tributação pela mesma entidade caracteriza o bis in idem. Quando se tratar de múltipla ou dupla tributação vários sujeitos ativos ou entidades tributantes, caracteriza-se bitributação, vedada pela Constituição.” (Eduardo Marcial Ferreira Jardim, Dicionário Jurídico Tributário, Saraiva, São Paulo, 1995, pág.14).”

Ressalta-se que o bis in idem é lícito, tendo como exceção apenas a situação de que seja ultrapassada alguma limitação constitucional. Em contrapartida, a bitributação é sempre inconstitucional, por violar limitações constitucionais e até mesmo competências tributárias. Sendo assim, pode-se dizer então, que a cobrança do imposto de importação no desembaraço aduaneiro de produtos estrangeiros importados, em face da cobrança, também no mesmo ato, do imposto de importação, não caracteriza a bitributação, mas simplesmente um bis in idem, que no caso não viola nenhuma limitação constitucional, partindo-se da premissa que IPI e II pertencem à competência tributária da União Federal. Nesse sentido, Hugo de Brito Machado, defende que:

\footnotetext{
'... a cobrança do imposto de importação no desembaraço aduaneiro de produtos estrangeiros importados, em face da cobrança, também no mesmo ato, do imposto de importação, não caracteriza a bitributação, mas simplesmente um bis in idem, que no caso não viola nenhuma limitação constitucional. Como assevera José Roberto Vieira, não obstante esse deslize de técnica jurídica que permitiu a invasão do campo de um, pelo outro imposto, certo é que não se deu violação da discriminação constitucional de competências tributárias, pois tanto um como o outro imposto pertencem à competência de uma só pessoa política, a União, configurando-se um adicional do outro, a nosso ver sem nenhum conflito com a Constituição . (...)In Comentários ao Código Tributário Nacional, artigos $1^{\circ}$ a 95, volume I, jurídico atlas, p. 476)" (REsp No 846.667 - RJ, Ministro HUMBERTO MARTINS, DJ: 07/03/2007)
}

Não há, com isso, no desembaraço aduaneiro de produtos importados, uma completa superposição do IPI e do imposto de importação. A superposição é apenas parcial, pois o âmbito constitucional de incidência do imposto de importação é a importação de produtos estrangeiros, que não abrange a importação de produtos brasileiros exportados.' (In Comentários ao Código Tributário Nacional, artigos $1^{\circ}$ a 95 , volume I, jurídico atlas, p.

476) " (REsp Nº 846.667 - RJ , Ministro Humberto Martins, DJ: 07/03/2007) 


\section{COMPRA DE VEÍCULO AUTOMOTOR NO BRASIL $X$ COMPRA DE VEÍCULO AUTOMOTOR NO EXTERIOR}

É um fato notório que adquirir um carro no Brasil, atualmente, é caro. Poucos brasileiros têm ideia da quantidade de tributos que são recolhidos ao Estado brasileiro, integrantes do preço final, na compra de um veículo novo. Com base neste fato, segue abaixo tabela pontuando quais são os impostos incidentes na compra de automóvel novo por pessoa física no Brasil, levando-se em consideração a recente decisão do STF em seu RE n. 723.65.

\begin{tabular}{|c|c|c|}
\hline$\underline{\text { IMPOSTOS }}$ & $\begin{array}{ll}\text { VEÍCULO } & \text { OKM } \\
\end{array}$ & VEÍCULO OKM IMPORTADO DO EXTERIOR \\
\hline TAXADOS & NACIONAL & \\
\hline ICMS & $\begin{array}{c}\text { INCIDE E VARIA DE } \\
\text { ESTADO PARA ESTADO }\end{array}$ & INCIDE \\
\hline IPI & INCIDE & $\begin{array}{l}\text { PASSOU A INCIDIR COM A DECISÃO DO RE } \\
\text { n. } 723.65\end{array}$ \\
\hline II & NÃO INCIDE & INCIDE \\
\hline $\begin{array}{c}\text { COFINS/PIS/ } \\
\text { PASEP }\end{array}$ & INCIDE & INCIDE \\
\hline
\end{tabular}

Analisando a tabela acima não restam dúvidas que é muito mais vantajoso para o consumidor adquirir automóvel novo nacional. Além de ser tributado com um imposto a menos em relação à aquelas pessoas que importam veículos do exterior, o imposto de importação, é notório o fato de que essa foi a maneira encontrada pelo governo federal para proteger a indústria nacional da invasão de produtos e bens estrangeiros com sua repercussão no mercado laboral. 


\section{PRINCÍPIOS CONSTITUCIONAIS APLICÁVEIS: A ESCOLHA DE SOFIA ${ }^{2}$}

Os princípios constitucionais que norteiam o Imposto sobre Produtos Industrializados ampliam o enfoque sobre o tema. Podendo citar, como os mais relevantes o da isonomia e o da não cumulatividade. Cada um deles utilizados de forma individual, como parte fundamental da justificativa de entendimentos do Supremo Tribunal Federal, para embasar seus posicionamentos, tanto o ultrapassado, que versa sobre a não incidência do IPI na importação de veículos do exterior, como em seu entendimento atual, que defende o oposto.

Antes do RE 723.651, como o entendimento majoritário dos tribunais era a favor na isenção da cobrança do IPI, o princípio da não cumulatividade era utilizado com mais frequência e desempenhava maior importância quando comparado ao princípio da isonomia. Hoje, após recente decisão do RE 723.651, o entendimento a cerca do mesmo caso passa a ser outro, e, com isso, o princípio a ser adotado para defesa de tal tese também. Resta claro a prevalência do princípio da isonomia perante o da não cumulatividade. Fato este que será explicitado adiante após analise de cada um destes princípios relacionados na defesa da cobrança ou não do IPI, juntamente com decisões proferidas pelo STF.

No que diz respeito ao princípio da não cumulatividade, podemos dizer que, a não cumulatividade do IPI, disciplinada no artigo 49 do CTN e disposta no artigo art. $153, \S 3^{\circ}$, II da Constituição Federal, que enuncia que este imposto não é cumulativo, permitindo-se a compensação do que for devido em cada operação com o montante cobrado nas anteriores, é obrigatória. Ricardo Alexandre, define este principio como sendo:

A não cumulatividade é técnica que tem por objetivo limitar a incidência tributária nas cadeias de produção e circulação mais extensas, fazendo com que, a cada etapa da cadeia, o imposto somente incida sobre o valor adicionado nessa etapa. Assim, no final da cadeia, o tributo cobrado jamais será maior que o valor da maior alíquota, multiplicado pelo valor final da mercadoria. (ALEXANDRE, Ricardo. Direito tributário esquematizado. 6 ed. Rio de Janeiro: Forense; São Paulo: Método, 2012, p. 547.)

\footnotetext{
2 Publicado em 1979, com três milhões de exemplares vendidos, este clássico moderno relata, o drama comovente e aterrador de Sofia Zawistowka, uma polonesa sobrevivente do campo de concentração de Auschwitz. O romance é em parte autobiográfico, ao narrar o envolvimento de Stingo, um jovem aspirante a escritor, com a bela Sofia, assombrada pela terrível escolha que precisou fazer um dia e que não somente definiu o resto da sua vida, como também se tornou uma expressão idiomática: fazer uma "escolha de Sofia" significa ver-se forçado a optar entre duas alternativas igualmente insuportáveis. Mais informações sobre o tema disponíveis em: < http://geracaoeditorial.com.br/escolha-de-sofia-a/ >acesso em:25 de março de 2016.
} 
O princípio da não cumulatividade possuí como principal objetivo o impedimento de oneração excessiva ou desproporcional da cadeia produtiva, efeito cascata, fazendo incidir a diferença basicamente sobre o valor agregado na venda de cada etapa, além da realização de justiça fiscal.

Na maioria das vezes em que a jurisprudência, o STF, o STJ e o TRF fizeram uso deste princípio em suas decisões, foi no sentido da isenção do IPI na importação de carros de luxo.

Hoje, após radical mudança de entendimento sobre a incidência na importação do Imposto sobre produtos industrializados, o Supremo Tribunal Federal, entendeu, por maioria, que incide o Imposto sobre Produtos Industrializados na importação de automóveis por pessoas físicas para uso próprio, uma vez que a cobrança do IPI não afronta o princípio da não cumulatividade nem implica bitributação. A manutenção de sua incidência, por outro lado, preserva o princípio da isonomia, uma vez que promove igualdade de condições tributárias entre o fabricante nacional, já sujeito ao imposto em território nacional, e o fornecedor estrangeiro.

O princípio da isonomia significa igualdade perante a lei. Sendo definido com base em duas acepções, uma vertical e outra horizontal, encontra-se disposto no art. 150, II da CF, ao prescrever a vedação de tratamento desigual entre contribuintes que se encontrem em situações equivalentes, proibindo qualquer forma de distinção em razão de ocupação profissional ou função por eles exercida, independentemente da denominação jurídica dos rendimentos, títulos ou direitos.

Por sua acepção horizontal, compreende-se aquelas pessoas que estão niveladas na mesma situação, devendo assim, serem tratadas da mesma forma. Por sua vez, a acepção vertical diz respeito aquelas pessoas que se encontram em situações distintas e, por isso, devem ser tratadas de maneira diferenciada na medida em que se diferenciam.

Ressalta-se que, no artigo 150, II, o legislador se ateve ao conceito de isonomia em seu sentido horizontal. O princípio da isonomia é um dos maiores princípios do meio jurídico, uma vez que visa assegurar uma política democrática. Rui Barbosa entende que:

\footnotetext{
"A regra da igualdade não consiste senão em quinhoar desigualmente aos desiguais, na medida em que se desigualam. Nesta desigualdade social, proporcionada à desigualdade natural, é que se acha a verdadeira lei da igualdade... Tratar com desigualdade a iguais, ou a desiguais com igualdade, seria desigualdade flagrante, e não igualdade real."
} 
Em se tratando do IPI na importação de veículos para uso pessoal, o principio da isonomia se encontra presente quando é cobrado o tributo na compra de veiculo automotor, vindo do exterior no momento em que observamos que tal tributação é necessária para haver isonomia de tratamento tributário entre a indústria estrangeira e a nacional. Caso contrário, se não fosse tributado o IPI na compra de veículos automotores do exterior, as indústrias nacionais se encontrariam em desvantagem e teriam grandes prejuízos financeiros. Tratando as duas indústrias (nacionais e estrangeiras) de forma igual, estaríamos de certa forma protegidos e, nessa situação, beneficiando a economia brasileira, uma vez que sendo tributado o IPI os números de veículos comprados do exterior reduziriam e, com isso, os brasileiros passariam a dar preferência em adquirir veículos da indústria nacional.

Aliomar Baleeiro acredita que o importador de produtos industrializados realiza o fato gerador do Imposto sobre Produtos Industrializados e sua não incidência geraria desequilíbrio econômico no mercado interno, em total desconformidade ao princípio da isonomia tributária:

(...) a incidência de tributos como o imposto sobre produtos industrializados (IPI) e o imposto sobre operações de circulação de mercadorias e serviços (ICMS) na importação não tem nenhum objetivo protecionista, mas é fenômeno necessário de isonomia e equidade. É que, já vimos, a norma adotada no mercado internacional é aquela de desoneração das exportações, de tal modo que os produtos e serviços importados chegam aos países do destino livre de todo imposto. Seria agressivo à regra da libre concorrência e aos interesses nacionais pôr imposição desfavorável à produção nacional, que sofre a incidência do IPI e do ICMS. (BALEEIRO, 2002 , p.341)

Juliane Stival, em sua obra A Exegese do Princípio da Neutralidade Fiscal no Sistema Tributário Nacional, sobretudo no regime da substituição tributária, na concessão de incentivos fiscais e na elisão fiscal, defende a prevalência do princípio da isonomia dizendo que:

Ao se permitir tratamento não uniforme entre contribuintes que pretendem adquirir veículos importados, por via oblíqua interfere-se nas relações econômicas, não só de concorrência[7] - abrindo uma janela imprevisível e prejudicial de atrito entre o mercado interno e externo -, mas no amplo contexto de disparidade social, na medida em que os mais favorecidos pagam menos, enquanto os menos favorecidos pagam mais, tornando o sistema tributário ainda mais regressivo do que já é. Ademais, a importação de carros de luxo com isenção, concomitante a venda do "carro popular" a uma alíquota elevada, ofende frontalmente o princípio da seletividade, da isonomia e da neutralidade fiscal.`(Stival, Juliane. A exegese do principio da neutralidade fiscal no sistema tributário nacional, sobretudo no regime da substituição tributária na concessão de incentivos fiscais e na elisão fiscal. Disponível em: 
Humberto Ávila, em sua obra Teoria dos Princípios, defende que princípios tradicionais de vários ramos do Direito têm sido flexionados em razão de outros princípios, considerados como 'maiores' ou 'mais importantes. Isso ocorre e pode ser justificado partindo-se do pressuposto de que não há princípios absolutos e que todos eles podem ceder em favor de outros princípios considerados, diante do caso concreto, mais importantes ou com peso maior. Segundo o autor, nem todos os princípios exercem as mesmas funções, nem todos se situam em um mesmo nível e nem todos possuem a mesma eficácia. Frisa-se que, em todas essas situações citadas, os princípios não entram em colisão horizontal uns com outros e nem se submetem a uma ponderação que possa levar ao seu afastamento. O que ocorre é uma atribuição de peso aos princípios que entram em conflito e são criadas regras de prevalência entre eles diante de um caso concreto.

Com base no exposto, paira a dúvida, ou melhor dizendo, nos deparamos no dilema da "'escolha de Sofia"' para escolher qual dos princípios possui maior relevância perante o outro.

Para solucionar tal emblema, nos deparamos com a seguinte análise: o principio da isonomia, por ser considerado como sendo um princípio estruturante, possui eficácia permanente, linear e resistente. O princípio da isonomia, deverá sempre ser observado e não pode, em hipótese alguma, ser afastado por razão contraditória. Este princípio exige a relação entre dois sujeitos, com base numa medida de comparação, para se atingir uma determinada finalidade. A sua observância não é propriamente gradual e suas exigências não podem ser afastadas por razões contrárias. Segundo o entendimento adotado pela maioria dos ministros do STF, a cobrança do IPI é admitida uma vez que preserva o princípio da isonomia, uma vez que promove igualdade de condições tributárias entre o fabricante nacional, já sujeito ao imposto em território nacional, e o fornecedor estrangeiro.

O princípio da não cumulatividade em contrapartida, não comporta da mesma força que o da isonomia. Isso porque, no sistema normativo constitucional a não cumulatividade é excepcional, e não regra. Não só porque se aplica apenas ao ICMS e IPI, mas também porque a própria Constituição definiu ser obrigatória apenas a novos impostos e contribuições para a seguridade social. Este motivo também impede que se enxergue a não cumulatividade como sendo um princípio enquanto norma informadora de toda a ordem jurídica. 
Além disso, pode-se dizer que até mesmo em se tratando do IPI, a sua representatividade, atualmente, no cenário nacional é menor. ${ }^{3}$ Isso vem ocorrendo, principalmente, da ênfase a ele atribuída pela possibilidade de excepcionar a anterioridade ( aet.150, paragrafo primeiro) e a legalidade ( art. 153, paragrafo primeiro). Em virtude disto, a não cumulatividade tornou-se para o IPI, um princípio de caráter secundário. É por este ponto de vista que, podemos afirmar que o principio da isonomia prevalece em relação ao da não cumulatividade. E, é assim, neste contexto que deve ser entendida a recente decisão do STF em relação à aplicabilidade do IPI na compra de veículos importados. A decisão visa colocar em condições de igualdade tributária o fabricante nacional e o fornecedor estrangeiro, uma vez que o primeiro já era sujeito ao imposto em território nacional.

\section{REFORMULAÇÃO DO STF SOBRE A MATÉRIA}

Antes do RE 723651, o entendimento do STF e STJ era da não incidência do IPI na compra de veículos importados do exterior. Um desses entendimentos controversos, a título de exemplo, é o de Silva ${ }^{4}$, que afirma delinear-se no Superior Tribunal de Justiça e no Supremo Tribunal Federal uma preocupante tendência que, se confirmada, acarretará sérios prejuízos à indústria nacional, além de causar grave ofensa ao Princípio da Isonomia insculpido no art. 150, inciso II, da Constituição Federal de 1988, ao tratar de forma desigual os consumidores de produtos industrializados no exterior e os consumidores de produtos industrializados no país.

Esses julgados estão embasados na ofensa do Princípio da não-cumulatividade pela impossibilidade de se compensar o imposto devido em cada operação com o montante cobrado nas anteriores. Não sendo comerciante, a pessoa física não pratica atos que envolvam circulação de mercadorias.

\footnotetext{
3 O IPI representou 4,15\% da carga tributária em 2002, estimada em 35,75\% do PIB, conforme registra Bordin (BORDIN, Luiz Carlos Vitali. Padrões tributários no Brasil. Estudos Econômicos-Fiscais. Porto Alegre, v.9, n.44, mar.2003,p.23). 4 SILVA, Arnaud da. Não incidência do IPI nas Importações Efetuadas por Pessoas Físicas. Desoneração do IPI nas importações efetuadas por pessoas físicas. Decisões recentes do STJ e do STF.
} 
Contudo, Silva se opõe aos fundamentos desses julgados, que se baseiam na interpretação da Constituição Federal, em seu art. 153 incisos e parágrafo 3, alegando o ferimento ao Princípio da Isonomia, por acreditar que, eles tratam de forma desigual as mercadorias produzidas no mercado interno, e que efetivamente incidem o IPI e as mercadorias produzidas no mercado exterior e importadas por pessoa física, as quais não deverá incidir o IPI.

É um fato notório que a Receita Federal exige o IPI na importação de todo e qualquer bem industrializado, independente do importador ser ou não contribuinte do imposto. Ocorre que, o importador pessoa física, não é considerado como sendo contribuinte do imposto, pois sua exigência atenta contra o princípio da não cumulatividade, uma vez que a pessoa física não pode usufruir os créditos gerados pela exação.

O não aproveitamento do imposto para geração de créditos ocorre, uma vez que, como pessoa física, o consumidor final do produto importado, não terá sobre o seu bem qualquer ato posterior de industrialização, sendo inviável a compensação do IPI recolhido como crédito de uma posterior.

O princípio constitucional da não cumulatividade existe para evitar a superposição do mesmo imposto sobre a mesma mercadoria ou serviço, o que tornaria o valor final do produto ou serviço extremamente onerosa. Em face deste princípio o pagamento do imposto anterior sobre um serviço ou produto é lançado como crédito, utilizando este crédito na incidência do novo imposto na saída da mercadoria de seu estabelecimento.

Neste sentido, o artigo 46, do Código Tributário Nacional, em seu inciso I, fere o princípio da não cumulatividade quando se trata de importação tendo, como destinatário do produto pessoa física, a qual não poderá utilizar-se do benefício da compensação do imposto pago.

Com esta fundamentação, o STF e cortes federais, entenderam até então, que não era cabível a cobrança de Imposto Sobre Produtos Industrializados sobre o desembaraço aduaneiro, de produtos importados por pessoas físicas, para utilização particular.

Em contrapartida, o julgamento, ocorrido no dia 03 de fevereiro do corrente, representa radical mudança de entendimento sobre a incidência, na importação do Imposto sobre produtos industrializados. Isso porque até o momento, tanto o STF como o STJ entendiam que não incidia IPI na importação de veículos para uso próprio. Como exemplo desta posição que era, até então defendida, podemos citar o STJ em sede de recurso especial repetitivo: "É firme 
o entendimento no sentido de que não incide IPI sobre veículo importado para uso próprio, tendo em vista que o fato gerador do referido tributo é a operação de natureza mercantil ou assemelhada e, ainda, por aplicação do princípio da não cumulatividade.” (STJ. 1ª Seção. REsp 1396488/SC, Rel. Min. Humberto Martins, julgado em 25/02/2015) e o STF, adotando esta mesma posição em seus recursos: RE 550170 AgR, Rel. Min. Ricardo Lewandowski, julgado em 7/6/2011; RE 255090 AgR, Rel. Min. Ayres Britto, julgado em 24.8.2010.

Sendo assim, o mais recente posicionamento para a questão é:

\section{INCIDE O IPI EM IMPORTAÇÃO DE VEÍCULOS AUTOMOTORES POR PESSOA NATURAL, AINDA QUE NÃO DESEMPRENHE ATIVIDADE EMPRESARIAL, E O FAÇA PARA USO PRÓPRIO. $S_{T F}^{5}$. Plenário. RE 723651/PR, Rel. Min. Marco Aurélio, julgado em 03/02/2016.}

Apesar do tribunal justificar a decisão utilizando-se do princípio da isonomia, feriu o mandamento constitucional de que o imposto obedece a não cumulatividade, de modo que o contribuinte pessoa física que realizar a compra de veículos para uso próprio não poderá se creditar do imposto pago, haja vista que não haverá repasse do produto. Para aplicar o princípio da isonomia, nessa hipótese, o imposto será cumulativo desobedecendo o que preconiza Constituição Federal, o que podemos concluir é que, ao final, quem arcará com o maior ônus tributário, mais uma vez, será contribuinte.

\footnotetext{
${ }^{5}$ Para melhor aprofundamento sobre a matéria, recomenda-se leitura do artigo: MODULAÇÃO DOS EFEITOS DA DECISÃO DO STF PARA O CALCULO DA COBRANÇA DO IPI, disponível em:

http://www.stf.jus.br/portal/cms/verNoticiaDetalhe.asp?idConteudo=309265. Acesso em: 5/03/2016.
} 


\section{CONCLUSÃO}

A discussão acerca da incidência do Imposto sobre Produtos Industrializados na importação de automóveis por pessoas naturais é de suma importância e tem tomado grande relevância nos debates tributários nos últimos meses. A matéria tem grande peso para importadores de automóveis. ${ }^{6}$

Muitos discutiram sobre a constitucionalidade dessa incidência. Inicialmente, em um primeiro julgamento, o Supremo Tribunal Federal entendeu que a sua incidência seria inconstitucional, por afrontar o princípio da não cumulatividade. Esse entendimento ocasionou em diversas ponderações de princípios e regras constitucionais, tal qual a isonomia sob a perspectiva da não-cumulatividade e sob a ótica do tratamento de produtos nacionais e estrangeiros.

A violação ao principio da não-cumulatividade na hipótese, tendo em vista que o adquirente do produto importado não poderá dar vazão ao credito adquirido, foi motivo decisivo no primeiro posicionamento do STF que entendeu sobre a não incidência do imposto.

Porém, posteriormente, em um julgamento iniciado em novembro de 2014 e retomado no inicio de fevereiro do corrente, este posicionamento mudou. Com repercussão geral reconhecida, o STF julgou o RE 723651, entendendo que o imposto incide na importação de veículo por pessoa física, ainda que seja para uso próprio, sob a justificativa de que a exação não estaria afrontando a não cumulatividade, e estaria aplicando o princípio da isonomia, visando a igualdade de condições tributárias entre o fabricante nacional, já sujeito ao imposto em território nacional, e o fornecedor estrangeiro. Caso houvesse a isenção haveria ameaça a livre concorrência, com prejuízos para as montadoras do país.

Por fim, analisamos que o princípio da isonomia tem prevalência perante o principio da não cumulatividade, sendo assim, utilizado como justificativa do recente posicionamento a cerca do caso.

\footnotetext{
Número de importações
http://carros.uol.com.br/noticias/redacao/2014/05/08/burocracia-dificulta-importar-carro-mas-preco-final-podeAcesso em 16/03/16.
} 
A decisão do STF em tributar o IPI na compra veículos do exterior alcançará tanto as operações de importação que vierem a ser realizadas no futuro, quanto as importações que foram realizadas antes do julgamento realizado em fevereiro.

A decisão trouxe um caos jurisprudencial e, de certa forma uma insegurança jurídica pois, apesar do julgamento ter sido realizado em sede de Recurso Repetitivo, (artigo 543-B do Código de Processo Civil), ele está longe de firmar a questão, partindo do pressuposto que o Superior Tribunal de Justiça apreciou a mesma matéria em sede de Recurso Repetitivo há menos de um ano, seguido da jurisprudência majoritária de diversos outros Tribunais Regionais Federais, bem como nos Juízos de primeira instância, que entendem de forma diversa da interpretação dada pela maioria do Supremo.

Resta agora, acompanharmos as futuras movimentações a cerca do caso para ver como será concluído, em caráter definitivo, a questão da incidência do Imposto sobre Produtos Industrializados no que diz respeito à importação de veículos do exterior por pessoa natural.

\section{REFERENCIAS BIBLIOGRÁFICAS}

ALEXANDRE, Ricardo. Direito tributário esquematizado. 6 ed. Rio de Janeiro: Forense; São Paulo: Método, 2012, p. 547.

ANDRADE, Rita de Cássia. Visão do IPI como instrumento de arrecadação e de políticas extrafiscais de interferência no domínio econômico e seus reflexos sociais. 2010. disponível em http://www.netlegis.com.br, acesso em 15.mar.2016.

ÁVILA, Humberto. Teoria dos Princípios: da definição à aplicação dos princípios jurídicos. $5^{\text {a }}$ edição. Rio de Janeiro: Malheiros, 2006.

BALEEIRO, Aliomar. Direito tributário brasileiro. $11^{\mathrm{a}}$ ed., Rio de Janeiro: Forense, 2002.p.341

BARBOSA, Rui. Oração aos Moços. Martin Claret: São Paulo, 2003.

BORDIN, Luiz Carlos Vitali. Padrões tributaries no Brasil. Estudos Econômicos-Fiscais. Porto Alegre, v.9, n.44, mar.2003,p.23

BORGES, Humberto Bonavides. Manual de procedimentos tributários IPI, ICMS e ISS: guia prático do gerente, consultor e analista tributário das empresas. $3^{\mathrm{a}}$ ed. São Paulo: Atlas, 2009.

BRASIL. Código Tributário Nacional. São Paulo: Saraiva, 2015.

BRASIL. Constituição da República Federativa do Brasil. São Paulo: Saraiva, 2015. 
BRASÍLIA. Supremo Tribunal Federal. Repercussão Geral em Recurso Extraordinário n723651, Relator: Min. Marco Aurélio, Julgamento em 11/04/2013. Disponível $<$ http://stf.jus.br/portal/jurisprudencia/listarJurisprudencia.asp?s 1=\%28723651\%2ENUME\%2 $\mathrm{E}+\mathrm{OU}+723651 \% 2 \mathrm{EPRCR} \% 2 \mathrm{E} \% 29 \&$ base=baseRepercussao\&url=http://tinyurl.com/cq9f9h> Acesso em 5 mar 2016.

BUROCRACIA DIFICULTA IMPORTAR CARRO, MAS PREÇO FINAL PODE COMPENSAR. Disponível em: :

http://carros.uol.com.br/noticias/redacao/2014/05/08/burocracia-dificulta-importar-carro-maspreco-final-pode-compensar.htm . Acesso em 16/03/16.

FERREIRA JARDIM, Eduardo Marcial. Dicionário Jurídico Tributário, $21^{\text {a }}$ edição, São Paulo: Saraiva.1995. pág.14

GOUVÊA, Marcus de Freitas. A Incidência do Imposto sobre Produtos Industrializados na Importação de Veículos Automotores Destinados a Consumidor Final. Revista Dialética de Direito Tributário. São Paulo, no . 195, p.89, dez. 2011.

IPI É DEVIDO SOBRE IMPORTAÇÃO DE AUTOMÓVEIS POR PESSOA FÍSICA, DECIDE STF. Disponível em:

$<$ http://www.stf.jus.br/portal/cms/verNoticiaDetalhe.asp?idConteudo=309265 $>$ acesso em:10/03/2015.

MACHADO, Hugo de Brito. Crédito do IPI Relativo a Entrada de Insumos Adquiridos em Operação Isenta. Revista Dialética de Direito Tributário. São Paulo, nº 184, p.44-56, jan.2011.

MACHADO, Hugo de Brito. Curso de Direito Tributário. 29a ed. rev. atual e ampliada, São Paulo: Malheiros, 2008.

MODULAÇÃO DOS EFEITOS DA DECISÃO DO STF PARA CALCULO DA COBRANÇA DO IPI. Disponível em:

$<$ http://www.stf.jus.br/portal/cms/verNoticiaDetalhe.asp?idConteudo=309265>. Acesso em: 5/03/2016.

O IPI, o princípio da não cumulatividade e a importação de veículos para uso pessoa.

Disponível em: < https://jus.com.br/artigos/36042/o-ipi-o-principio-da-nao-cumulatividade-ea-importacao-de-veiculos-para-uso-pessoal\# ftn11.> acesso em 10/03/15.

PORTAL DA RECEITA FEDERAL DO BRASIL. Tabela TIPI. Disponível em:

<http://www.receita.fazenda.gov.br/publico/tipi/TIPI.doc> Acesso em 7/03/2016.

SABBAG, Eduardo. Manual de Direito Tributário. Edição Atualizada. São Paulo: Saraiva, 2013.p.1071 e 1072.

SABBAG, Maristela Miglioli. In RT. Competência tributária. São Paulo, jun. 1996, v. 728, p. 695

SILVA, Arnaud da. Não incidência do IPI nas Importações Efetuadas por Pessoas 
Físicas. Desoneração do IPI nas importações efetuadas por pessoas físicas. Decisões recentes do STJ e do STF.

SUPREMO NEGA ISENÇÃO DE IPI SOBRE CARRO IMPORTADO PARA USO PESSOAL. Disponível em: < http://g1.globo.com/economia/noticia/2016/02/supremo-negaisencao-de-ipi-sobre-carro-importado-para-uso-pessoal.html $>$ acesso em 8/03/16. Stival, Juliane. A exegese do principio da neutralidade fiscal no sistema tributário nacional, sobretudo no regime da substituição tributária na concessão de incentivos fiscais e na elisão fiscal. Disponível em:

$<$ http://www.ambitojuridico.com.br/site/index.php?n> acesso em: 1 